\title{
GLOBAL MODELING OF THE CONTRAIL AND CONTRAIL CIRRUS CLIMATE IMPACT
}

By UlRIKe BurkHardt, Bernd Kärcher, AND UlRICH SCHUMANN

Modeling the physical processes governing the life cycle of contrail cirrus clouds will substantially narrow the uncertainty associated with the aviation climate impact. et al. 2010). For the given ambient conditions, their direct radiative effect is mainly determined by coverage and optical depth. The microphysical properties of contrail cirrus likely differ from those of most natural cirrus, at least during the initial stages of the contrail cirrus life cycle (Heymsfield et al. 2010). Contrails form and persist in air that is ice saturated, whereas natural cirrus usually requires high ice supersaturation to form (Jensen et al. 2001). This difference implies that in a substantial fraction of the upper troposphere contrail cirrus can persist in supersaturated air that is cloud free, thus increasing high cloud coverage. Contrails and contrail cirrus existing above, below, or within clouds change the column optical depth and radiative fluxes. They may also indirectly affect radiation by changing the moisture budget of the upper troposphere, and therefore the microphysical properties and the frequency of occurrence of natural cirrus.

Global radiative forcing resulting from persistent linear contrails has been calculated using either reanalyses data in combination with radiative transfer codes or within a climate model. It is estimated to amount to $0.012 \mathrm{~W} \mathrm{~m}^{-2}$ for 2005 ( $42 \%$ of the radiative forcing of the accumulated aviation $\mathrm{CO}_{2}$ emissions), with an uncertainty range of $0.005-0.026 \mathrm{~W} \mathrm{~m}^{-2}$ and with a low level of scientific understanding (Lee 
et al. 2009). Current modeling studies are based on an approach that cannot be used to estimate contrail cirrus radiative forcing because the method is not suited to the simulation of long-lived contrail cirrus and because of the lack of contrail cirrus observations (Burkhardt et al. 2008a, section 2e). Radiative forcing resulting from AIC has been estimated to range between 0.013 and $0.087 \mathrm{~W} \mathrm{~m}^{-2}$ (Lee et al. 2009), exceeding that of past aircraft $\mathrm{CO}_{2}$ emissions. The effect of AIC has been estimated from observational data and the level of scientific understanding is judged to be very low. Modeling studies of the climate impact of aviation soot cirrus remain inconclusive because of the uncertainties in soot abundance and ice-nucleating properties (Hendricks et al. 2005; Penner et al. 2008; Liu et al. 2009). Therefore, we will not discuss this issue any further in this paper, even though the effect potentially may be important.

\section{CURRENT SCIENTIFIC UNDERSTANDING} AND UNCERTAINTIES. Studies of contrail cirrus (including the early line-shaped stage) need to bridge spatial scales from tens of meters to thousands of kilometers and temporal scales from seconds to days, covering their entire life cycles. Occasionally line-shaped contrails have been tracked for up to $17 \mathrm{~h}$ in satellite observations (Minnis et al. 1998). Encompassing such scales poses a great challenge for experimental and modeling efforts. Ground- and satellite-based remote sensing, aircraft measurements, and numerical models have been used to study contrails as long as they are line shaped, which is typically during the first few hours after formation (Heymsfield et al. 2010; Yang et al. 2010), because contrail cirrus is often indistinguishable from natural cirrus. This period represents only a fraction of the total life cycle of contrail cirrus. Contrail cirrus may be advected over long distances; the vertical shear of the horizontal wind spreads individual contrails,

AFFILIATIONS: BURKHARDT, KÄRCHER, AND SCHUMANN-Institut für Physik der Atmosphäre, Deutsches Zentrum für Luft- und Raumfahrt (DLR), Oberpfaffenhofen, Wessling, Germany CORRESPONDING AUTHOR: Ulrike Burkhardt, Institut für Physik der Atmosphäre, Deutsches Zentrum für Luft- und Raumfahrt (DLR), Oberpfaffenhofen, 82234 Wessling, Germany E-mail: ulrike.burkhardt@dlr.de

The abstract for this article can be found in this issue, following the table of contents.

DOI:10.1175/2009BAMS2656.I

In final form 15 September 2009

(O)2010 American Meteorological Society increasing the horizontal coverage, and the evolution of ice supersaturation determines the growth and decay of contrail cirrus.

Global radiative forcing resulting from persistent linear contrails has been estimated using a climate model or a combination of model and observations. The methodology is depicted in Fig. 1. Contrail formation conditions are well known and for a given aircraft they depend on temperature, pressure, and water vapor concentration (Schumann 1996). Formation conditions of persistent contrails have been parameterized either by using assumptions about the models' subgrid-scale variability of relative humidity or being based on empirically deduced thresholds. When combining the resulting frequency of formation conditions (potential contrail coverage) with an air traffic inventory, the formation frequency has been diagnosed and scaled to obtain linear contrail coverage in agreement with observed linear contrail coverage over a particular region. Assuming the scaling coefficient to be globally constant, the global linear contrail coverage has been derived. Radiative forcing has been estimated by diagnosing the contrail optical depth within a climate model by treating the vertical overlap and optical properties in the same way as for natural cirrus (Ponater et al. 2002). Alternatively, constant optical depth has been assumed globally (Rädel and Shine 2008).

The use of a globally constant scaling factor to estimate linear contrail coverage and the assumptions made about the optical properties of contrails are physically questionable. Air traffic movements and meteorological fields, determining contrail formation, spreading, and lifetime, vary strongly, implying that the scaling factor is temporally and regionally variable. Optical properties are not well constrained by observations, and assuming a constant optical depth is not realistic. Uncertainties regarding the contrail coverage and optical depth need to be studied systematically. Nevertheless, until now the same method has always been used, the scaling region has not been varied, and optical depth has been fixed in most studies. Most important, the scaling method cannot be generalized to simulate contrail cirrus because, unlike linear contrails, no observations of contrail cirrus coverage yet exist; furthermore, the scaling method is not able to take into account physical processes such as advection, processes determining the evolution of ice water content, and regional differences in contrail cirrus life times. In order to estimate the effect of future increased air traffic, global linear contrail radiative forcing has been extrapolated using aircraft fuel consumption or distance flown. 
Such estimates may be increasingly problematic because background climate, aircraft fleet, and flight patterns change.

The realistic simulation of contrail cirrus (including linear contrails) and natural clouds mainly depends on the moisture fields in the upper troposphere (Burkhardt et al. 2008a, section 3c). Climate models exhibit commonly significant moisture biases in the upper troposphere/lower stratosphere and do not explicitly allow for ice supersaturation, which is essential in simulating formation, persistence, and optical properties of ice clouds. Ice supersaturation has been either explicitly represented in a numerical weather prediction model prescribing an empirical ice nucleation threshold, while retaining simplified ice microphysics (Tompkins et al. 2007), or its fractional area has been parameterized in a global climate model (Burkhardt et al. 2008b). Using an estimate of the ice-supersaturated area, the life cycle of contrail cirrus can be simulated. Alternatively, in models with prognostic natural cloud coverage, interactions between contrail cirrus and natural clouds could be simulated more realistically. Aircraft wake processes are not realistically parameterized in largescale models, and therefore properties of contrails shortly after formation are not well constrained. In order to calculate the radiative effect of contrail cirrus (including linear contrails), assumptions about the contrail-cloud overlap and about particle optical properties need to be made. Maximum random overlap that is assumed for natural clouds may not be consistent with observations, and the overlap between natural clouds and contrail cirrus is even more uncertain (Burkhardt et al. 2008a, section 2e). Radiation schemes have not yet been adapted to contrails regarding contrail spatial geometry, effective ice particle sizes and shapes, which are known to differ from those of natural cirrus (Yang et al. 2010).

In addition to modeling efforts, new tools and datasets covering high-resolution upper-tropospheric absolute and relative humidity (including ice supersaturation frequency) are needed for constraining model parameterizations. Only recently have satellitederived datasets of relative humidity become available (Read et al. 2007; Lamquin et al. 2009), but they suffer from uncertainties connected with the retrieval, so that derivations using different satellite instruments can deviate considerably. Satellites have been used to study linear contrails, yielding statistics of regional contrail coverage and optical depth. Most studies used variants of a single detection algorithm (Mannstein et al. 1999). Its performance, in terms of false identification of natural cirrus and detection efficiency of narrow and optically thin contrails, depends on the satellite sensor and atmospheric conditions and varies strongly between the studies (Burkhardt et al. 2008a, section $2 \mathrm{~d}$ ). Therefore, the resulting observational datasets are difficult to intercompare. Neither can the geometrical shapes of individual clouds be simulated in large-scale models, nor can the fraction of linear contrails to contrail cirrus, or the duration of the period for which contrails remain linear, be known from observations. Validation of linear contrail coverage and optical depth is further hampered by variable and unspecified optical depth detection thresholds of satellite sensors (Kärcher et al. 2009). In situ measurements give us clues about ice water content and ice particle number concentrations, size, and shape, but statistics may be biased toward optically thicker contrails that are easily detectable. Numerical process studies that can give us clues about particle number concentrations and ice water content are available only for the early stages of the contrail life cycle (Jensen et al. 1998; Burkhardt et al. 2008a, section 2a). Observations of radiative flux changes resulting from contrails are scarce but are needed for validation.

Generally, simulations of contrail cirrus properties are even harder to evaluate because it is difficult to observationally distinguish between contrail cirrus and natural cirrus. Therefore, it is important to base climate model simulations of contrail cirrus on the parameterization of physical processes that may be 
better represented in the model and may be more easily evaluated. This may be done directly in a largescale model or by nesting a high-resolution model. In either case, resulting cirrus and contrail cirrus fields depend on the performance of models simulating ice particle formation, growth, and sedimentation, the moisture budget, vertical wind, wind shear, and turbulence in the upper troposphere.

THE WAY FORWARD. It is important to develop modeling approaches for deriving the global climate impact of contrail cirrus (including linear contrails). Those methods should be based on the parameterization of physical processes that treat contrail cirrus consistently with natural clouds. A process-based approach has recently been developed that allows the simulation of the contrail cirrus life cycle, including interactions and feedbacks with existing cirrus and the other atmospheric fields (Burkhardt and Kärcher 2009). In the long term, it may be even more important to improve cloud schemes, in particular regarding cirrus (Kärcher and Burkhardt 2008). Initial steps have been taken to implement parameterizations that link ice nucleation processes within cirrus to upper-tropospheric ice supersaturation in large-scale models (Lohmann and Kärcher 2002; Liu et al. 2007). Improvements in the representation of the moisture field, including ice supersaturation, together with suitable observational datasets for validation are also required for a realistic estimation of the climate effect of contrail cirrus. As an alternative to the modeling approach, satellite retrievals may be used to infer changes in high cloudiness and radiative fluxes resulting from aviation, which not only benefits contrail cirrus but also general climate research.

For validation purposes, more upper-tropospheric meteorological datasets are needed. In addition to standard meteorological parameters, these include absolute and relative humidity, vertical wind, and cloud microphysical variables. Furthermore, globally homogeneous long-term datasets of linear contrail coverage and optical depth, and measurements of microphysical and optical properties of evolving contrails are required. Because it is difficult to validate simulations of contrail coverage obtained from large-scale models with observations, high-resolution numerical weather prediction models combined with plume dispersion models may be useful for validating climate model parameterizations. Validation may also utilize measurements of radiative fluxes in the presence of contrails. Data that are available from recently launched spaceborne and new airborne instruments should be exploited to better constrain microphysical and radiative properties of ice clouds and ice supersaturation.

Reducing the contrail cirrus radiative forcing is an effective means of reducing the aviation climate effect on a short time scale. This may be achieved by modifying jet engine particulate emissions, affecting contrail formation and initial contrail properties (Kärcher and Yu 2009), and by directing air traffic to avoid areas of contrail formation or persistence (Mannstein et al. 2005). Contrail forecasting, in conjunction with high-resolution weather forecasts and an online $4 \mathrm{D}$ aircraft emission inventory, will help to avoid those areas, at the cost of, for example, increased fuel consumption. Mitigation strategies need to minimize the climate effect resulting from all types of emissions. In order to devise a sensible mitigation strategy, it is important to define on which time scale the climate effect is supposed to be minimized and with which metric the climate effect is measured (Wuebbles et al. 2010).

ACKNOWLEDGMENTS. This study is based on the Subject Specific White Paper written in connection with ACCRI funded by the Federal Aviation Administration through the U.S. Department of Transportation Volpe Center Contract (DTRT57-07-C-10056). The ACCRI program is sponsored by the Environmental Working Group of the U.S. NextGen Joint Planning and Development Office. This work was performed within the DLR Project "Climate-compatible air transport system" ("CATS"). Editorial assistance was provided by Dr. Meg Miller.

\section{REFERENCES}

Brasseur, G., and M. Gupta, 2010: Impact of aviation on climate: Research priorities. Bull. Amer. Meteor. Soc., 91, 461-464.

Burkhardt, U., and B. Kärcher, 2009: Processbased simulation of contrail cirrus in a global climate model. J. Geophys. Res. 114, D16201, doi:10.1029/2008JD011491.

,,-- H. Mannstein, and U. Schumann, 2008a: Climate impact of contrails and contrail cirrus. ACCRI Key Theme 5 SSWP, FAA, 58 pp. [Available online at www.faa.gov/about/office_org/headquarters_ offices/aep/aviation_climate/media/ACCRI_SSWP_ IV_Burkhardt.pdf.]

- _ - M. Ponater, K. Gierens, and A. Gettelman, 2008b: Contrail cirrus supporting areas in model and observations. Geophys. Res. Lett., 35, L16808, doi:10.1029/2008GL034056. 
Duda, D. P., P. Minnis, and L. Nguyen, 2001: Estimates of cloud radiative forcing in contrail clusters using GOES imagery. J. Geophys. Res., 106, 4927-4937.

Hendricks, J., B. Kärcher, U. Lohmann, and M. Ponater, 2005: Do aircraft black carbon emissions affect cirrus clouds on the global scale? Geophys. Res. Lett., 32, L12814, doi:10.1029/2005GL022740.

Heymsfield, A., D. Baumgardner, P. DeMott, P. Forster, K. Gierens, and B. Kärcher, 2010: Contrail microphysics. Bull. Amer. Meteor. Soc., 91, 465-472.

Jensen, E. J., A. S. Ackerman, D. E. Stevens, O. B. Toon, and P. Minnis, 1998: Spreading and growth of contrails in a sheared environment. J. Geophys. Res., 103, 132557-132567.

__ and Coauthors, 2001: Prevalence of ice-supersaturated regions in the upper troposphere: Implications for optically thin ice cloud formation. J. Geophys. Res., 106, 172253-172266.

Kärcher, B., and U. Burkhardt, 2008: A cirrus cloud scheme for general circulation models. Quart. J. Roy. Meteor. Soc., 134, 1439-1461.

— and F. Yu, 2009: The role of aircraft soot emissions in contrail formation. Geophys. Res. Lett., 36, L01804, doi:10.1029/2008GL036649.

—, U. Burkhardt, S. Unterstrasser, and P. Minnis, 2009: Factors controlling contrail cirrus optical depth. Atmos. Chem. Phys., 9, 6229-6254.

Lamquin, N., K. Gierens, C. J. Stubenrauch, and R. Chatterjee, 2009: Evaluation of upper tropospheric humidity forecasts from ECMWF using AIRS and Calipso data. Atmos. Chem. Phys., 9, 1779-1793.

Lee D. S., D. W. Fahey, P. M. Forster, P. J. Newton, R. C. N. Wit, L. L. Lim, B. Owen, and R. Sausen, 2009: Aviation and global climate change in the 21st century. Atmos. Environ., 43, 3520-3537.

Liu, X., J. E. Penner, S. J. Ghan, and M. Wang, 2007: Inclusion of ice microphysics in the NCAR Community Atmospheric Model version 3 (CAM3). J. Climate, 20, 4526-4547.

,-- , and M. Wang, 2009: Influence of anthropogenic sulfate and black carbon on upper tropospheric clouds in the NCAR CAM3 model coupled to the IMPACT global aerosol model. J. Geophys. Res., 114, D03204, doi:10.1029/2008JD010492.
Lohmann, U., and B. Kärcher, 2002: First interactive simulations of cirrus clouds formed by homogeneous freezing in the ECHAM GCM. J. Geophys. Res., 107, 4105, doi:10.1029/2001JD000767.

Mannstein, H., R. Meyer, and P. Wendling, 1999: Operational detection of contrails from NOAA AVHRR data. Int. J. Remote Sens., 20, 1641-1660.

_- P. Spichtinger, and K. Gierens, 2005: A note on how to avoid contrail cirrus. Transp. Res., D10, 421-426.

Minnis, P., D. F. Young, D. P. Garber, L. Nguyen, W. L. Smith Jr., and R. Palikonda, 1998: Transformation of contrails into cirrus during SUCCESS. Geophys. Res. Lett., 25, 1157-1160.

Penner, J. E., Y. Chen, M. Wang, and X. Liu, 2008: Possible influence of anthropogenic aerosols on cirrus clouds and anthropogenic forcing. Atmos. Chem. Phys. Discuss., 8, 132903-132942.

Ponater, M., S. Marquart, and R. Sausen, 2002: Contrails in a comprehensive global climate model: Parameterization and radiative forcing results. J. Geophys. Res., 107, 4164, doi:10.1029/2001JD000429.

Rädel, G., and K. P. Shine, 2008: Radiative forcing by persistent contrails and its dependence on cruise altitudes. J. Geophys. Res., 113, D07105, doi:10.1029/2007JD009117.

Read, W. G., and Coauthors, 2007: Aura Microwave Limb Sounder upper tropospheric and lower stratospheric $\mathrm{H}_{2} \mathrm{O}$ and relative humidity with respect to ice validation. J. Geophys. Res., 112, D24S35, doi:10.1029/2007JD008752.

Schumann, U., 1996: On conditions for contrail formation from aircraft exhausts. Meteor. Z., 5, 4-23.

Tompkins, A., K. Gierens, and G. Rädel, 2007: Ice supersaturation in the ECMWF Integrated Forecast System. Quart. J. Roy. Meteor. Soc., 133, 53-63.

Wuebbles, D., P. Forster, H. Rogers, and R. Herman, 2010: Issues and uncertainties affecting metrics for aviation impacts on climate. Bull. Amer. Meteor. Soc., 91, 491-496.

Yang, P., G. Hong, A. Dessler, S. Ou, K. Liou, P. Minnis, and Harshvardhan, 2010: Contrails and induced cirrus: Optics and radiation. Bull. Amer. Meteor. Soc., 91, 473-478.

\section{TELL YOUR COLLEAGUES!}

Our new simplified application form makes joining the AMS easier than ever!

Applications are now being accepted online at www.ametsoc.org. 


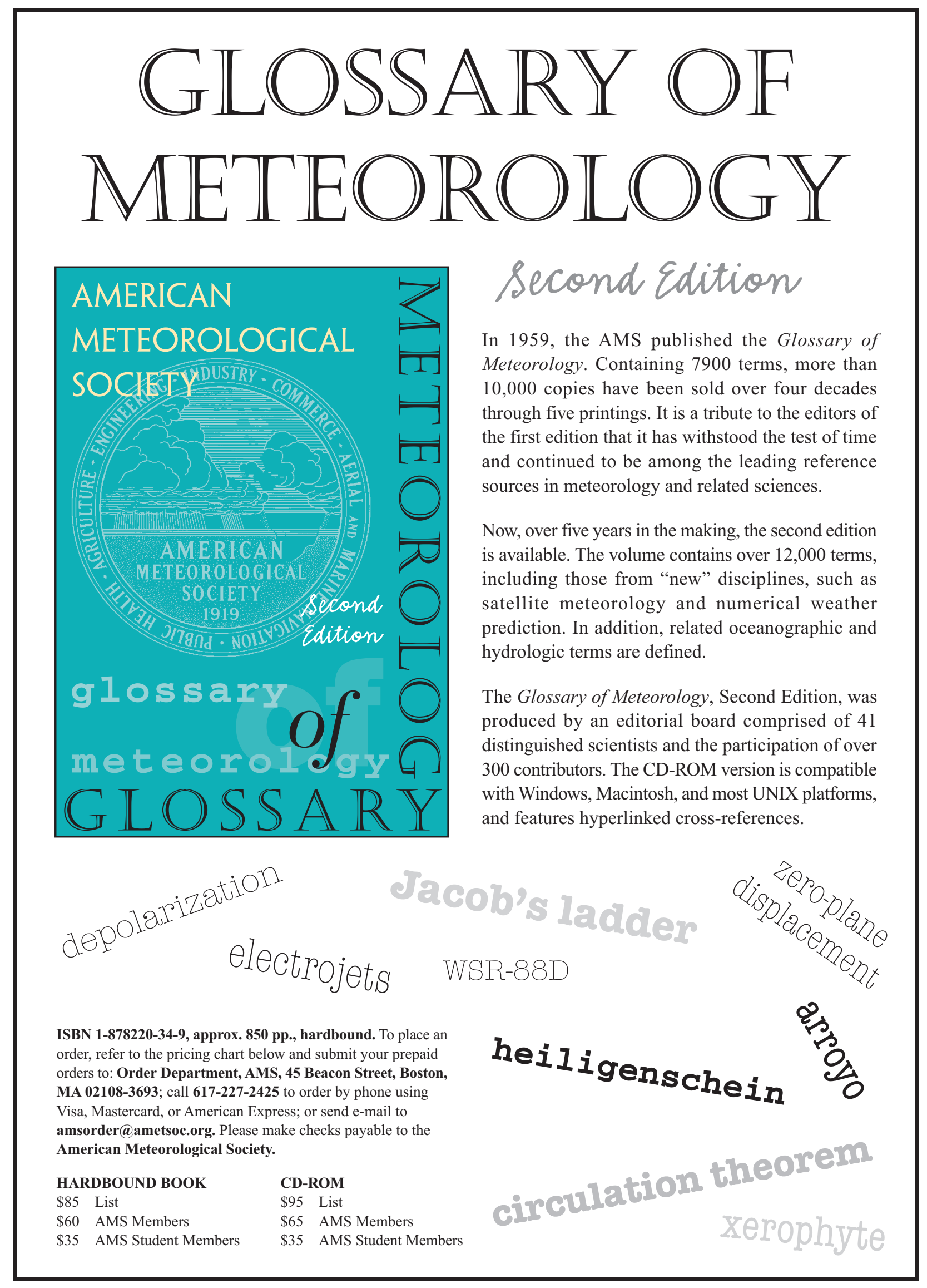

